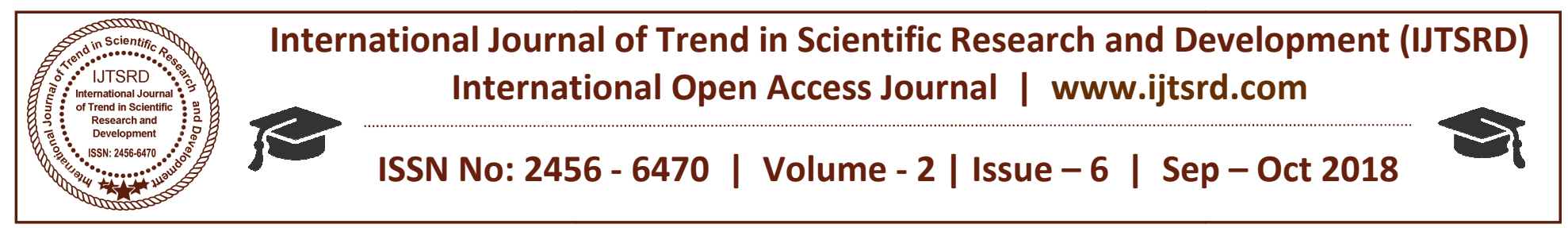

\title{
Review Paper on Study on Properties of Black Cotton Soil using Rice Husk Ash
}

\author{
Aashish Gautam ${ }^{1}$, Pratiksha Malviya ${ }^{2}$ \\ ${ }^{1}$ M.Tech Scholar, ${ }^{2}$ Professor \\ Department of Civil Engineering, Millennium Institute of Technology, \\ Bhopal, Madhya Pradesh, India
}

\begin{abstract}
The growing cost of traditional stabilizing agents and the need for the economical utilization of industrial and agricultural wastes for beneficial engineering purposes has prompted an investigation into the stabilizing potential of Rice Husk Ash in subgrde soil. These Large Quantities of Waste Materials Rice Husk Ash e.g. create negative impact on the environment causing air pollution, water pollution, affecting the local eco- system and hence safe disposal of this waste material is required. Utilizing these waste materials as alternative materials for the construction is no doubt a best solution.
\end{abstract}

Keyword: Natural Soil, Rice Husk Ash, Swelling, OMC, $M D D, C B R$, Atterberg limits.

\section{INTRODUCTION}

Soil is basic and important element in Civil Engineering field. Stability of every structure depends on the type and characteristics of foundation which in turn depends on the type of soil. Many problems irrupt if expansive soil, Natural soil is to be used in foundation, because of its shrinkage and swelling properties. There are many methods to make natural soil stable for various constructions. Natural soil is comfortable for road work, compared to other types of soil. There are two ways to enhance the quality of subgrade soil "Replacement of soil" or "Soil stabilization". Soil stabilization can be done chemically or mechanically. Chemical stabilization is carried out by adding different chemicals in suitable proportion, while Mechanical stabilization is achieved by addition of admixtures which helps to improve the properties of soil.

\section{Pavement}

Pavement is the flat part of the road on which people and traffic move. Generally, a pavement consists of few layers with different materials. A pavement is, therefore defined as a relatively stable crust constructed over the natural soil for the purpose of supporting and distributing the wheel loads and providing an adequate wearing surface.

\section{Methods of Stabilization}

Currently several methods of soil stabilization are available with their own advantages and disadvantages. The engineer in charge has to decide a method or a combination of methods by considering the soil type, the needed engineering properties to be improved, and the type structure, and economy. Stabilization methods can be broadly classified into two main groups. They are mechanical and chemical. Additionally thermal and electrical methods are also considered on occasions. Important stabilization methods and their suitability are discussed in the following paragraphs.

\section{A. Mechanical Stabilization}

$>$ It is the Process of improving the properties of soil by changing its gradation.

$>$ Two or more natural soils are mixed to obtain a composite material which is superior to any of its components.

$>$ Mechanical stability of soil depends upon plastic characteristics, gradation of mixed soil, degree of compaction attained in the field.

\section{B. Chemical Stabilization}

It is the Stabilization done by adding different chemicals such as calcium chloride, sodium chloride, sodium silicate etc. 
$>$ Chemical Stabilization is more expansive than other types of stabilization.

\section{Lime Stabilization}

$>$ Lime is being used as a soil stabilizer since ancient times.

$>$ The hydrated lime $\mathrm{Ca}(\mathrm{OH})_{2}$ is the most commonly used lime for soil stabilization.

$>$ Lime is also used in combination with other stabilizers such as fly ash and cement.

$>$ Soil plasticity, density and strength are changed by adding lime to soil. Lime increases the plasticity index of low plastic soils and decreases the plasticity index of high plastic soils.

$>$ Almost all types of soils can be stabilized using lime.

\section{Cement Stabilization}

$>$ It is done by pulverized mixing soil and Portland cement with water and compacting the mix to attain a strong material.

$>$ In this stabilization, cement is mixed in a particular range about $5-14 \%$ by volume.

\section{E. Fly ash Stabilization}

$>$ Stabilization of soils by using fly ash and mixture of lime or cement and fly ash is gaining more importance in recent times since it has widespread availability.

$>$ This method is inexpensive and takes less time than other stabilization methods. Fly ash may be mixed with soil during excavation right in the field.

\section{F. Rice husk ash Stabilization}

$>$ Rice husk ash stabilization is done by adding Rice husk ash to soil. It is useful for stabilization of clayey soil.

\section{RELATED WORK}

\section{$>$ S. A. Naeini \& R. Ziaie Moayed et al (2009)}

in their study they prepared three types of soil samples with different percentage of bentonite on which CBR tests were carried with or without geogrid reinforcement in one or multilayer. Result shows that increase in plasticity index decreases the CBR value in both soaked and unsoaked condition. CBR can be considerably increased by using geogrid reinforcement in two layers when compared with unreinforced, but less value when compared with single layered reinforcement. By placing geogrid at layer 2 there is a considerable increase in CBR value compared with unreinforced soil in both soaked and unsoaked conditions. By using two layers of geogrid at layer 1 and 3, unsoaked CBR value increases compared with unreinforced soil. However this increment is much less when compared to the case when geogrid is placed at layer 2. Further, the soaked CBR value is higher than the value obtained for both single and no layer of geogrid.

\section{$>$ Dr Sujatha Evangelin Ramani (2012)}

provide geogrid reinforcement to improve the strength of subgrade and reduce the thickness of the pavement The author conducted CBR tests on soil with geogrid introduced at different depths within the sample, in single, double and triple layer and found that the best performance in the single layer occurs when geogrid is placed at $2 / 3$ distance from the base. And found that the CBR value of 3 layer of geogrid is lesser than 2 layer but higher than single layer and hence concluded that geogrid increases the strength of subgrade soil in both soaked and unsoaked condition and proved that geogrid reinforcement provided in a single or multilayer to the subgrade increases the strength of the soil and thus reduces the thickness of the pavement.

\section{Pradeep Singh and K. S. Gill (2012)}

Reinforced soils are often treated as composite materials in with reinforcement resisting tensile stress and interacting with soil through friction. Although there is lot of information and experience with geosynthetic reinforcement of sub-grade soils, many pavement failures still occur. These failures may be due to lack of understanding of how these materials influence the engineering properties of sub-grade soils and what is the optimum position of reinforcement. Therefore a compressive laboratory program is required to study strength characteristics of both reinforced and un-reinforced sub-grade soils also to investigate their behaviors under cycle leading. The author in his work describes the beneficial effects of reinforcing the sub-grade layer with a single layer of geo-grid at different positions and thereby determination of optimum position of reinforcement layer. The optimum position was determined based on California Bearing Ratio (CBR value) and unconfined compression tests were conducted to decide the optimum position of geo-grid. Through his experimental work he found that by providing geogrid reinforcement at $0.2 \mathrm{H}$ from top give considerable improvement in CBR value and stress strain behavior of sub grade soil. 
$>$ Mihai Iliescu and Ioan Ratiu (2013)

for subsoil with insufficient bearing capacity, stabilization and improvement of subsoil characteristics are necessary. The bearing capacity can be increased by excavation and replacement of the soft material, chemical stabilization by using chalk or by using geosynthetics. Placed between the subgrade and base course, or within the base course, the geosynthetic improves the performance of unpaved roads carrying channelized traffic and unpaved areas subjected to random traffic. They in their paper devised a new design methodology for stabilizing a road subgrade using geogrid reinforcement. In their experiments, they found out that geogrids can improve the performance of the Subgrade soil. They carried out extensive static and dynamic plate bearing tests on different conditions based on the results of trial and the membrane theory of Giroud \& Noiray, they developed design graphs for multifunctional geogrids in unpaved and temporary road.

\section{Rakesh Kumar and P.K. Jain (2014),}

Different ground improvement techniques have been proposed in the literature to work with this soil and are found to be successful to some degree. The construction of granular piles has been proved successful in improving soft marine clays, which are very poor from strength and compressibility criteria. The technique of granular pile may be applied in expansive soil too. The granular piles derive their load carrying capacity from the confinement offered by the surrounding soil. In very soft soils this lateral confinement may not be adequate and the formation of the granular pile itself may be doubtful. Wrapping the granular pile with suitable geogrid is one of the techniques to improve the performance of granular piles. The encasement by geogrid makes the granular piles stiffer and stronger. The behavior and the mechanism of the granular pile and geogrid encased granular piles are not investigated for expansive soil. The author made an attempt to investigate the improvement of load carrying capacity of granular pile with and without geogrid encasement through laboratory model tests conducted on single granular pile installed in expansive clay bed prepared in controlled condition in small testing tanks. The load tests were performed on single granular pile. Tests were performed with different diameter of granular piles with and without geogrid encasement. The results from the load tests indicated a clear improvement in the load carrying capacity of clay, with granular pile and with encased granular pile. The increase in the load carrying capacity also increases as the diameter of the granular pile increases. Thus concluded in their study of ground improvement techniques that the construction of granular piles in expansive soil improves the load carrying capacity of the soil,

Prof Mayura Yeole and Dr. J.R. Patil (2015), carried out a laboratory CBR test on granular soil with or without geotextile which was placed in one or two layer in the mould. The single layer of geotextile was placed at the depth of $(25,50,100 \mathrm{~mm})$ from the top of the mould, the maximum CBR obtained was at $25 \mathrm{~mm}$ and when the geotextile was placed in two layers at $\{(25 \& 75 \mathrm{~mm}),(50 \& 75 \mathrm{~mm}),(50 \& 100$ $\mathrm{mm})\}$ CBR was increased and it was maximum at 25 \& $75 \mathrm{~mm}$ geotextile layer by $38.21 \%$ when compared with the CBR of no geotextile.

\section{Problem Identification}

Today, world faces a serious problem of disposal of large quantities of agricultural and industrial waste like Rice husk ash, fly ash, stone dust. Sugarcane bagasse ash etc. The disposal of these wastes without proper attention creates hazardous impact on environmental health. So Rice husk ash used in this project because these waste materials are also low cost.

\section{Objective}

To determine the Geotechnical properties of Natural Soil, RHA individually, for the construction of sub grade soil.

\section{CONCLUSION}

The results of percentage increment in Unsoaked CBR \& Soaked CBR goes on increasing with respect to Natural Soil when RHA is increased from 0 to $10 \%$ and is decreases when RHA Sample is increased.

\section{REFERENCES}

1. AmbarishGhosh (2010) "Compaction characteristics and bearing ratio of pond ash stabilized withlime and phosphogypsum.” Journal of Materials in Civil Engineering, ASCE, 343351.

2. Al-Rawas, A.A., Taha, R., Nelson, J.D., Al-Shab, T.B., and Al-siyabi, H., (2002), "A Comparative Evaluation of Various Additives Used in Stabilization of Expansive Soils", Geotechnical Testing Journal, Vol. 25, No. 2, pp. 199-209 
3. Bell, F.G. 1996. Lime Stabilization of Clay Minerals and Soils, Engineering Geology; 42: 223-237.

4. Boominathan A, Ratna R.J. (1996) "Lime treated fly ash as embankment material." Proceeding of Indian Geotechnical Conference, Madras, India, 523-526.oceeding of Indian Geotechnical Conference (IGC 96), Madras, 411-414

5. Erdal Cokca (2001) "Use of Class C Fly ashes for the stabilization of an Expansive soil." Journal of Geotechnical and Geoenvironmental Engineering, ASCE, Vol. 127, 568-573.

6. Edil T.B., Acosta H.A., Benson C.H. (2006) "Stabilizing soft fine grained soils with fly ash." Journal of Materials in Civil Engineering, ASCE, Vol.18, 283-294.

7. Fredlum D.G.\&Rahardjo H.(1993)"soil mechanics for unsaturated soils. John willy \& sons Inc. Newyork.
8. Grim, R. E. (1968), Clay Mineralogy, 2nd edition, McGraw-Hill, New York.

9. I.S.2720 (Part iv)-1975, determination of grain size analysis.

10. I.S. 2720 (Part v)-1970, determination of liquid limit \& plastic limit.

11. I.S. 2720 (Part viii)-1965, determination of maximum dry density and optimum water content

12. Ingles, O.G., and Metcalf, J.B. (1972), Soil stabilization principles and practice, Butterworth, Sydney, Australia.

13. J.N. Jha et al (2006) "Effect of Rice Husk Ash on Lime Stabilization." Journal of Institute of Engineers (India), Volume 87, 33-3

14. Këhew, E.A., (1995), Geology for Engineers and Environmental Scientists, 2nd Ed. Prentice Hall Englewood Cliffs, New Jersey, pp. 295-302

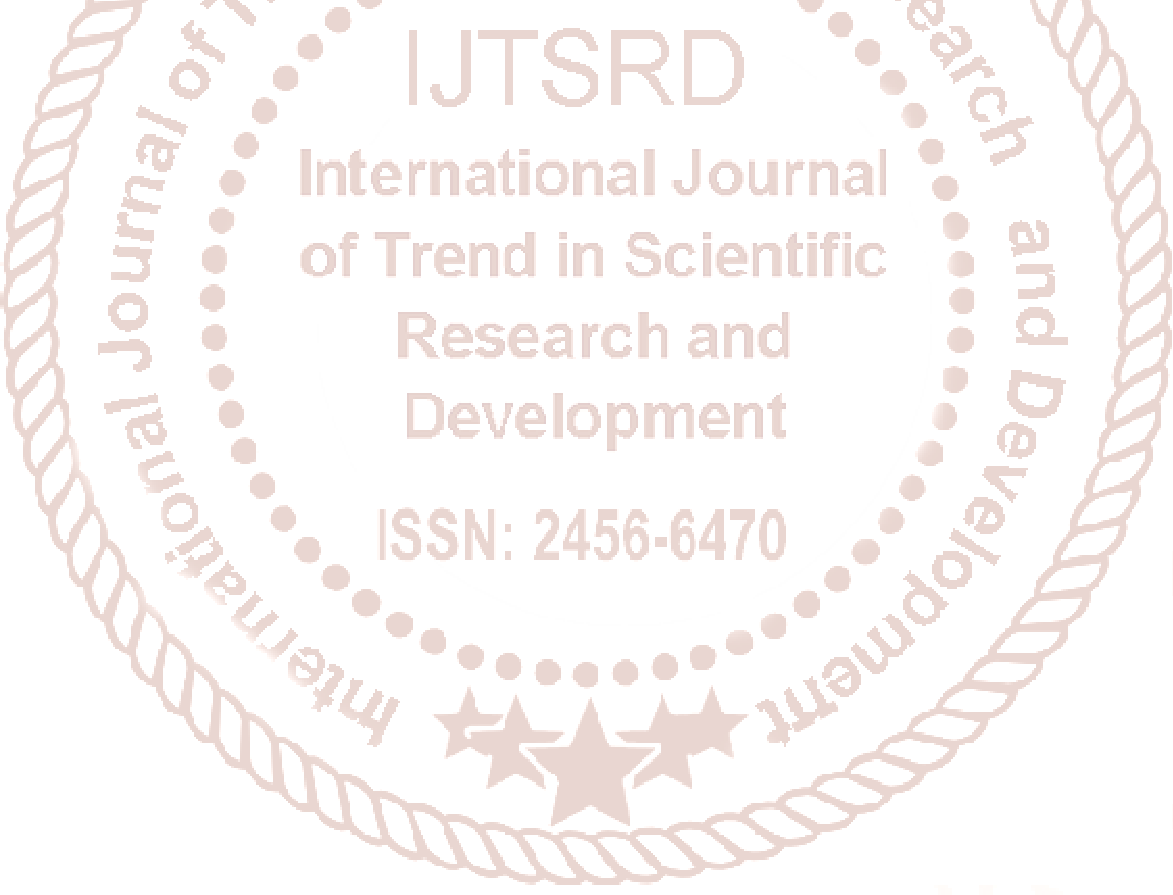

